\title{
Use of knowledge brokering services in the innovation process
}

DOI:

10.1109/ICMIT.2012.6225817

Link to publication record in Manchester Research Explorer

\section{Citation for published version (APA):}

Malik, K. (2012). Use of knowledge brokering services in the innovation process. In 2012 IEEE 6th International Conference on Management of Innovation and Technology, ICMIT 2012/IEEE Int. Conf. Manage. Innov. Technol., ICMIT (pp. 273-278). IEEE. https://doi.org/10.1109/ICMIT.2012.6225817

\section{Published in:}

2012 IEEE 6th International Conference on Management of Innovation and Technology, ICMIT 2012|IEEE Int. Conf. Manage. Innov. Technol., ICMIT

\section{Citing this paper}

Please note that where the full-text provided on Manchester Research Explorer is the Author Accepted Manuscript or Proof version this may differ from the final Published version. If citing, it is advised that you check and use the publisher's definitive version.

\section{General rights}

Copyright and moral rights for the publications made accessible in the Research Explorer are retained by the authors and/or other copyright owners and it is a condition of accessing publications that users recognise and abide by the legal requirements associated with these rights.

\section{Takedown policy}

If you believe that this document breaches copyright please refer to the University of Manchester's Takedown Procedures [http://man.ac.uk/04Y6Bo] or contact uml.scholarlycommunications@manchester.ac.uk providing relevant details, so we can investigate your claim.

\section{OPEN ACCESS}




\title{
Use of knowledge brokering services in the innovation process
}

\author{
Khaleel Malik ${ }^{1}$ \\ ${ }^{1}$ MIoIR, Manchester Business School, University of Manchester, Manchester, UK \\ (e-mail:khaleel.malik@mbs.ac.uk)
}

\begin{abstract}
This paper investigates the use of knowledge brokers who provide a technology intelligence brokering service to help firm's access external knowledge for their innovation process, especially as part of 'search and scanning' . This is seen as an important intermediation role. The paper provides an overview of the different functions of 'knowledge brokers' that have emerged to assist firms with innovation by connecting clients with external partners with a view to better informing the 'search and scanning' activities of the client firms. Two case studies presented here help to illustrate how UK manufacturing firms have benefitted from using intermediary organizations such as management consultants and Research Technology Organizations as part of their search and scan activities.
\end{abstract}

Keywords - intermediaries, knowledge brokering, search and scan.

\section{INTRODUCTION}

A growing body of thought argues that in a competitive era in which success depends increasingly upon the ability to produce new or improved products and processes, external knowledge acquisition constitutes an important basis for innovation-based value creation. Openness to new ideas and solutions is considered essential for innovation projects, especially for firms moving towards an open innovation business model. In turn this is associated with increasing levels of external collaboration and outsourcing, which strongly links to the effective acquisition of knowledge from external business relationships $[1,2]$. In the area of 'searching/ scanning' external knowledge sources with a view to internalizing this knowledge, a more prominent type of knowledge brokering services have emerged that include organizations providing technology intelligence and information exchange to their clients [3, 4]. Here it should be mentioned that 'search/scan' is often seen as an activity undertaken during the fuzzy front-end phase of the innovation projects [5]. This is a critical phase for two reasons. First, the foundation for success or failure is often established before a new concept enters the subsequent formal development process. Second, many firms lack proficiency in the way front-end activities are executed [6]. Altogether, previous research has shown that these activities have a major impact on final new product or process development success.
The role of intermediaries and the process of intermediation has also been explored in the context of service activity, in particular in relation to the growth of Knowledge Intensive Business Services (KIBS) [7, 8]. Many KIBS firms have close and continuous interactions with their clients which can involve crucial, but largely hidden, functions in supporting innovative change within their client companies [9]. In the context of this paper, we view business-related intermediaries as 'knowledge brokers' who act as bridges for innovation to other manufacturing and service firms, in line with Wolpert [10].

The paper proceeds as follows. Section II provides an overview of key literature strands relating to external partnering, search and scanning, and intermediation all in context of the innovation process. Section III presents the methodological approach used in this research study. Section IV presents findings from two case studies that help to illustrate the role of intermediaries when acting as knowledge brokers. Sections V and VI provides some theoretical and practical based implications and conclusions that are relevant to innovation management.

\section{THEORETICAL BACKGROUND}

\section{A. External partnering for innovation collaboration}

The literature indicates that there are many potential knowledge advantages associated with external collaborative partnerships $[11,12]$. Sometimes some knowledge may be obtained in no other way than through partnering with a firm that has control over an important technology [13]. Thus, there is great potential value associated with pursuing a knowledge accumulation and creation strategy through the use of some form of knowledge brokering service. Often the decision-making criteria of the firm revolve around whether to use external collaborative partnerships to gain knowledge and/ or an assessment of the costs associated with potential knowledge gains and losses [14, 15]. After a decision has been made to collaborate with an external partner, often the next step is to formalise the informal initial collaboration in terms of setting up a contractual agreement [16]. Some studies have analyzed this contractual aspect for technology transfer agreements, where for example, Watkins and Horley [17] identified the role played by intermediary organizations to identify technology transfer partners, help package the technology to be transferred between two firms, select suppliers to 
make components for the technology and provide support in making the deal between the firms concerned. In another technology transfer study, Seaton and CordeyHayes [18] highlighted the role of the Defence Technology Enterprise (DTE) as a knowledge broker involved in technology exploitation. This study showed how DTE interacted with their clients in the technology transfer process and demonstrated that brokering is more than just a linking role, as it also helps transform the ideas and knowledge being transferred.

\section{B. Search and scanning}

Technology managers are often faced with the dilemma of selecting a single most appropriate technology from a range of competing options. The rapid development of technologies, together with their increasing complexity and variety, has made the task of technology 'search and scanning' difficult. Shehabuddeen et al. [19] state that current approaches to the technology selection decision have usually been narrowly focused on assessment of the financial viability of technology options, or conventional investment justification factors. In many cases, the selection processes are based on generic decision support tools which are not fully adapted for technology selection. This emphasizes the view that a 'knowledge broker' might be utilized to help with search and scanning of the external environment because brokering is more than just a linking role. Hargadon and Sutton [3] also confirm that the role of a knowledge broker is not just one of supporting a linkage. In their study of IDEO a U.S. design consultancy, they emphasize that the role of the knowledge broker should be seen as a knowledge repository whose knowledge its workers use to provide solutions that are new combinations of existing ideas to their clients.

For large firms, even with sophisticated search machines and well-developed information and source libraries, it is often difficult for firms to adequately know what they 'know' [3]. Here it is important to stress that the scanning activity is also a learning process. As scanning and networking activity builds up it helps to increase an organization's awareness of externally developed technology, and also to reduce search times [20].

\section{Innovation intermediation}

There is some evidence to suggest that innovation intermediation' has grown over recent times. Howells [4] confirms that although organizations providing an 'innovation intermediation' function tend to remain specialized around particular activities, the range of services being offered does appear to be increasing over time. In addition, the organizations providing intermediation functions do not solely or even wholly restrict themselves to intermediary functions, but also cover more traditional contract research and technical services which involve no third party type collaboration. Bessant and Rush [9] highlight the more interactive and diagnostic role of consultants acting as intermediaries.
These consultants, therefore, help define and articulate the needs of the client in relation to innovation. This includes articulation and selection of technology options; scanning and locating new sources of knowledge; building linkages with external knowledge providers; development and implementation of business and innovation strategies.

When adopting solutions from other industry sectors, companies mainly rely on an intermediary organization to share their experience in product development and industrialization and, thus, to reduce risks. The intermediary is expected to integrate the new technology into the customer's company through product development support and coaching, or even by implementing the solution himself. Some customers may also want an intermediary to possess experience of legal or intellectual property rights issues so that the intermediary could minimize their legal exposure [21].

One key theme of the literature relating to areas of external partnering for innovation and the search/ scanning process is that the acquisition of technological knowledge is a process that is closely linked to other business processes, and is more often associated with the broader technological, organizational and business environment. This aspect of knowledge acquisition is encompassed in the remainder of this paper.

\section{METHODOLOGY}

The research is based on two in-depth case studies that involved semi-structured interviews with managers in four British based organizations, based on specific project collaborations, together with their overall strategies and work practices. The primary survey material collected by interview was also supported by the collation and synthesis of secondary documents made available by the organizations. The case studies were oriented by a case study protocol developed prior to data collection, and information was collected in such a way as to allow triangulation on all relevant aspects of our research, by at least two different information sources [22]. Our case study discussions were informed by a prior review of technology and innovation management literature, and subsequent conceptual development. This research is interested in exploring how the use of technology intelligence brokering has been operationalized by industrial firms and knowledge brokering service providers?

Given that this was an exploratory study in part to help articulate what an innovation intermediary is. It was helpful to use the following working definition from Howells [4, p. 720], of an innovation intermediary during the case study interviews: "An organization or body that acts as an agent or broker in any aspect of the innovation process between two or more parties. Such intermediary activities include: helping to provide information about potential collaborators; brokering a transaction between two or more parties; acting as a mediator, or go-between, bodies or organizations that are already collaborating; and 
helping find advice, funding and support for the innovation outcomes of such collaborations."

\section{RESULTS}

\section{A. Management Consultant acting as knowledge broker}

In the first case study we learned that a UK-based management consultancy firm (for confidentiality purposes referred to as 'Consultant KBX') was not only providing 'one-off' intermediary services to its clients, but also seeking to offer longer term 'relational innovation' capabilities to them as well. As this type of collaboration can last for a number of years, rather than a few months, it provides opportunities for the intermediaries to get to know their clients better as well as to gain more lucrative, value added contracts. In our case study Consultant KBX provided advice to a major, process based glass manufacturing company (referred to here as 'Glass STH') on what external research links, especially collaborations with universities, that Glass STH would find valuable for its long-term development. This is, however, not just a simple scoping exercise of locating potentially useful research expertise in universities and other research centers. It also involves gaining a deeper knowledge of what Glass STH actually needs, identifying the client firm's core competencies, and then mapping potentially useful research linkages with this profile. This means identifying where external research capabilities could fill the current and future research and technological gaps (or areas of weakness) that the client company could not provide or would do better not providing itself. Glass STH make a variety of glass products ranging from coated/tinted glass which saves energy to toughened/ laminated safety glazing products.

If we analyze the results of the Consultant KBX and Glass STH collaboration within the 'search and scanning' stage of the innovation process, we found that even though Glass STH already had a strong working relationship with some universities; the firm were still interested in working with other universities who were researching in areas that were not considered to be core to Glass STH's current portfolio of research activities. Hence Glass STH commissioned Consultant KBX to conduct exploratory studies in areas that were linked indirectly to core technologies and R\&D activities of the client firm. For example Glass STH had been interested in the area of chemical vapor deposition and was able to ask Consultant KBX to identify university groups who had chemical expertise in this area. Consultant KBX managed the interface between Glass STH and its university contacts by firstly carrying out an audit of what interactions Glass STH managers had with universities and for what reasons. From gathering this information the consultant was able to match Glass STH's list of core competencies for the whole business process to establish which universities might be able to provide the expertise not currently found within Glass STH. The consultant was also able to identify some university academics working in areas that might influence the future competitiveness of Glass STH's business. For example, some of these academics were working in early research on advancements in nanotechnology.

Consultant KBX utilized several means to search for potential research partner organizations for their client. This involved sending out promotional leaflets to some research-intensive universities who may be interested in collaborating with Glass STH. The universities were identified from internet searching of research capabilities found in the universities to try and identify some universities with technical competence in areas where Glass STH did not possess such capabilities. Consultant KBX also sent staff to some international conferences and workshop events to help identify potential university collaborators. Consultant $\mathrm{KBX}$ was able to identify relevant conference/ workshop events because the company had some information on major science and technology conferences as a result of sitting on EPSRC committees. The EPSRC is the main UK government agency for funding research and training in engineering and the physical sciences.

We found that organizational diversity plays a particularly important role in terms of cultural, professional and technical backgrounds of staff employed in Consultant KBX. Despite having a relatively small number of permanent full time consultants (around 40 in total), Consultant KBX employs people from a variety of countries, with fluency in more than 15 different languages. Professional backgrounds cover different areas including, engineering, physics, electronics, biochemistry, mathematics, IT, psychology, economics, law and management. Professional experience, most of the times international, covers all the elements of bringing expertise in $\mathrm{R} \& \mathrm{D}$, operations, marketing, sales, finance, human resources, and logistics. More specifically, this multinational organization is built up of postgraduate scientists, technologists, business strategists, and qualitative research analysts, who combine commercial experience with technical understanding.

\section{B. Innovation and business support intermediary}

In the second case study we analyzed the role of a UK-based independent research and technology organization (for confidentiality purposes referred to as 'IBST') that employs 500 staff and has an annual turnover of $£ 45$ million (GBP). IBST helps its clients to innovate across the whole business cycle from products and processes, through business processes and people development, with the ultimate aim of improving competitiveness and increasing profitability.

IBST's Knowledge Services Division had developed an innovative search and solution engine, providing answers to research and technical queries inputted by managers from client companies. This is basically an information scanning and technology intelligence service, where the value is not only within the service content, but also in the direct access that it gives to IBST's staff, with wide experience of technology, manufacturing and 
business. The Knowledge Services Division of IBST benefitted from sharing some operational activities of this firm with the Technology Consulting arm of the company. This has enabled IBST to have built up the following capabilities in recent years: has access to more than 30,000 world business and industry news sources; access to full market research reports from over 200 providers; access to information on over 70 million global private and public companies; investment information from over 10 million industry analyst reports; access to over 17,000 technical peer reviewed journals; access to global patent and intellectual property information; access to analysis and forecasts on over 210 countries.

The 'search and solution technology' enabled IBST to archive substantial research information, which it sought to make more widely available to its global customer base. By charging for information on an ad-hoc basis, or on an account basis for registered members, these research archives become a cost effective source of information and advice for IBST's clients. Market research had led IBST to come to the conclusion that there was a real gap in the market for the high-value, operationally focused information and knowledge that could be applied to businesses to solve their problems. This project was seen as a considerable undertaking by IBST since it took some years to develop as the bulk of the information held was still on paper (with only summary and abstract sections in electronic format) and further complicated by the fact that customers accessing the search technology were using a range of different technologies and interfaces. This search technology is different from regular search engines found on the Internet. For many manufacturing firms, especially small firms, the Internet can be a confusing place to look for information. Hence one aim of the IBST search technology was to enable faster and reliable access to information sources for clients in the manufacturing industry as the bulk of the information already held was from this industry sector.

As search and scanning activity builds up it helps to increase an organization's awareness of externally developed technology. Often organizations can have too narrow a focus to recognize new opportunities or solutions to seemingly insurmountable problems. Hence one key attribute of the IBST solution was that it could identify technologies that can be transferred from one industry sector to another. This is seen as an important knowledge brokering service by one of IBST's clients from the medical devices sector, where one research manager commented: "The real benefit of the IBST search and solution service from our perspective is in the time saved in analyzing all the available information out there in the market and in helping us to assess the essential issues so that we make the right decisions".

\section{DISCUSSION}

The case studies suggest that finding a solution to a technology/ business problem via an intermediary organization is part of the larger process of scanning, selection, adoption and exploitation. This however, is a very important part according to Shehabuddeen et al. [19] since the selection decision has to take a forward view of how the chosen technology might impact the process of adoption and exploitation. It is also linked to the upstream process of scanning since options identified as a result of the scanning process may not be sufficient, in terms of variety or conformity, to be considered for selection. In connection with the 'selection decision' it is asserted in our cases that decision making is rarely, if ever, an optimal or perfectly rational process (from the perspective of the client firm who has approached the intermediary organization). Decision making in such conditions is made within a context of the manager developing and applying a few general principles and procedures, in practice, founded on a heuristic process, whereby people employ procedures that are efficient and that work most of the times, even though they sometimes lead to errors [23]. Hence highlighting the need to make more informed decisions around the external acquisition of knowledge, perhaps utilizing some form of a decision-making tool to help ensure that the right decision can be taken at the selection stage [24]. We see from the first case study how the input from the intermediary organization (Consultant KBX) actually helped the client firm (Glass STH) to make a more informed decision to partner with the most appropriate university research center. Hence this scanning activity became an important learning opportunity for Glass STH, not only learning about the university it eventually partnered with but also learning about other universities that were currently active in the field of research that was of interest to Glass STH, which was facilitated by the knowledge brokering service provided by Consultant KBX.

When adopting solutions from other industry sectors, as mentioned in our cases, companies often rely on the intermediary organization to help reduce uncertainties frequently found during the fuzzy front end of innovation. If uncertainty is not sufficiently reduced, it might eventually lead to concept failure, which can be costly at later stages of product development [25]. To reduce uncertainty, managers and project participants should continually engage in information acquisition and analysis regarding changes in technology, markets, internal organizational developments and priorities, external developments, and competitors [6]. This can all be facilitated when managers utilize the services of an intermediary, as indicated in our second case study.

In line with Howells [4] our cases confirm that the functions of an intermediary organization are more numerous, diverse and knowledge intensive than previous studies have implied. Intermediaries and their clients discover new needs and requirements for their intermediary roles. For example, moving from 
undertaking information scanning and technology intelligence to more fundamentally determining where to look in the first place, which might be better described as a foresight and diagnostics role. This also highlights the fact that innovation intermediaries can be considered to be a species of KIBS, especially given the knowledge brokering attributes of some intermediaries. Many KIBS firms have close and continuous interactions with their clients, which was a strong feature of the intermediaries analyzed in our case studies. This can be expressed as the combination of demand articulation, network brokerage and innovation process management functions that makes innovation intermediaries unique within the KIBS infrastructure of firms.

Here it also helpful to understand how the organizational structure and culture of the intermediary organizations studied here supports their knowledge brokering activities. The structure of work in knowledge brokering firms supports innovation because it exposes these organizations to a continual flow of new problems that often require novel solutions. A diverse client base ensures that the intermediary firms encounter a wide range of problems and solutions [26].

\section{CONCLUSION}

The intermediary organizations examined in this paper act as knowledge brokers, who attempt to exploit the value of existing knowledge by providing innovative solutions to clients in a variety of industry sectors that were perhaps unaware of the potential of that knowledge. Hence knowledge brokers can provide an increasing competitive advantage to those seeking innovation. Our findings can be linked to the ongoing open innovation debate, where insights into the role of innovation intermediaries (especially consulting firms) is quite limited and perhaps worthy of further research. Our research study attempted to contribute to a better understanding of the phenomenon and concept of the intermediary from a knowledge brokerage perspective. However, a better theoretical understanding of the determinants, enablers and barriers to intermediation within an open innovation setting is still required.

From the perspective of the firms acquiring new knowledge by working closely with intermediaries, the paper provides managerial implications for optimizing search and scanning activities in order to help reduce uncertainties with key decision making processes, especially when firms have to circumnavigate their way through the fuzzy front end of innovation projects. Managers must ensure that they have very good knowledge management systems in place that can help to capture key lessons arising from different internal project teams, which are often cross-functional teams that are assembled together quickly [27]. This also helps firms to capture the nature of the interaction between internal project teams and the external intermediary organizations to show which type of interactions have worked well in the past and which might not have worked so well.

The paper has shown that intermediaries provide a much more varied role for their clients in the innovation process than has generally been acknowledged. Hence this implies that there is also a wider range of innovation intermediation functions than has been usually considered. There is some evidence to suggest innovation intermediation is an activity that is growing over time. Although organizations providing such intermediation functions tend to remain specialized around particular actions, the range of services being offered does appear to be increasing over time. In addition, the organizations providing intermediation functions do not solely restrict themselves to intermediary functions, but also cover more traditional contract research and technical services which involve no third party type collaboration. This may also be linked to the fact that the intermediaries are built up of people with a variety of backgrounds and skills set, which often includes postgraduate scientists, technologists, business project managers, and research analysts, who are adept at combining commercial experience with technical understanding.

\section{REFERENCES}

[1] D. Chatterjee, "Accessing external sources of technology," Research Technology Management, vol. 39, no. 2, pp. 4856, 1996.

[2] J. Howells, A. James and K. Malik, "The sourcing of technological knowledge: distributed innovation processes and dynamic change," $R \& D$ Management, vol. 33, no. 4, pp. 395-409, 2003.

[3] A. Hargadon and R.I. Sutton, "Technology brokering and innovation in a product development firm," Administrative Science Quarterly, vol. 42, no. 4, pp. 718-749, 1997.

[4] J. Howells, "Intermediation and the role of intermediaries in innovation," Research Policy, vol. 35, no. 5, pp. 715-728, 2006.

[5] A. Khurana, and S.R. Rosenthal, "Integrating the fuzzy front end of new product development," Sloan Management Review, vol. 38, no. 2, pp. 103-120, 1997.

[6] J. Frishammar, H. Floren, and J. Wincent, "Beyond managing uncertainty: Insights from studying equivocality in the fuzzy front end of product and process innovation projects," IEEE Transaction on Engineering Management, vol. 58, no. 3, pp. 551-563, 2011.

[7] I. Miles, "Services innovation: coming of age in the knowledge-based economy," International Journal of Innovation Management, vol. 4, no. 4, pp. 371-389, 2000.

[8] P.A. Wood, "Knowledge-intensive services and urban innovativeness," Urban Studies, vol. 39, no. 5-6, pp. $993-$ 1002, 2002.

[9] J. Bessant, and H. Rush, "Building bridges for innovation: the role of consultants in technology transfer," Research Policy, vol. 24, no. 1, pp. 97-114, 1995.

[10] J. D. Wolpert, "Breaking out of the innovation box," Harvard Business Review, pp. 77-83, Aug. 2002.

[11] W. Powell, K.W. Koput, and L. Smith-Doerr, "Interorganizational collaboration and the locus of innovation: Networks of learning in biotechnology," 
Administrative Science Quarterly, vol. 41, no. 1, pp. 116145, 1996

[12] S.F. Matusik, and C.W.L. Hill, "The utilization of contingent work, knowledge creation, and competitive advantage," Academy of Management Review, vol. 23, no. 4, pp. 680-697, 1998.

[13] J. Grieve-Smith and J. Michie, Innovation, Cooperation and Growth. Oxford: Oxford University Press, 1998.

[14] C. Freeman, "Networks of innovators: a synthesis of research issues," Research Policy, vol. 20, no. 5, pp. 499$514,1991$.

[15] J. Tidd, and J. Bessant, Managing Innovation - Integrating Technological, Market and Organizational Change, Chichester: John Wiley \& Sons, 2009.

[16] S. Shohert M. Prevezer, "UK biotechnology: institutional linkages, technology transfer and the role of intermediaries," R\&D Management, vol. 26, no. 3, pp. 283298, 1996.

[17] D. Watkins and G. Horley, "Transferring technology from large to small firms: the role of intermediaries," in Small Business Research, T. Webb, T. Quince and D. Watkins, Eds. Aldershot: Gower, 1986, pp. 215-251.

[18] R.A.F. Seaton and M. Cordey-Hayes, "The development and application of interactive models of industrial technology transfer," Technovation, vol. 13, no. 1, pp. 4553, 1993.

[19] N. Shehabuddeen, D. Probert, and R. Phaal, "From theory to practice: challenges in operationalising a technology selection framework," Technovation, vol. 26, no. 3, pp. 324-335, 2006.

[20] P. Almeida, A. Phene, and R. Grant, "Innovation and knowledge management: Scanning, sourcing, and integration," in The Blackwell Handbook of Organizational Learning and Knowledge Management, M. Easterby-Smith, and M. Lyles, Eds. Oxford: Wiley-Blackwell, 2005, pp. 356-371.

[21] O. Gasssmann, M. Daiber, and E. Enkel, "The role of intermediaries in cross-industry innovation processes," $R \& D$ Management, vol. 41, no. 5, pp. 457-469, 2011.

[22] J. W. Creswell, Qualitative Inquiry and Research Design: Choosing among Five Approaches, Thousand Oaks: Sage, 2007.

[23] M.R. Klein and L.B. Methlie, L.B., Knowledge-based Decision Support Systems with Applications in Business, Chichester: John Wiley \& Sons, 1985.

[24] J. Howells, A. James and K. Malik, "Sourcing external technological knowledge: a decision support framework for firms," Int. J. Technology Management, vol. 33, no. 2/3, pp. 143-154, 2004.

[25] R. G. Cooper, "Perspective: The stage-gate idea-to-launch process Update, What's new, and NexGen systems," $J$. Product Innovation Management, vol. 25, no. 3, pp. 213232, 2008.

[26] A. Hargadon, "Firms as knowledge brokers: lessons in pursuing continuous innovation," California Management Review, vol. 40, no. 3, pp. 209-227, 1998.

[27] K. Malik, "Coordination of technological knowledge flows," Journal of Knowledge Management, vol. 8, no. 2, pp. 64-72, 2004. 